\title{
The partial and the vague as a visual mode in Bronze Age rock art
}

\author{
Fredrik Fahlander
}

\section{Introduction}

In archaeology most materials come in pieces; artefacts are broken, buildings are in ruins and imagery has become obscure from weathering and decay. This fragmentary nature of archaeological materials has traditionally been considered an empirical deficiency that should be overcome. To make sense of fragmentary remains, to reconstruct objects, to resolve issues of representation and to combine fragmented parts into meaningful wholes has thus been a key issue in archaeology. However, the view of fragments as parts of wholes tends to obscure the things that actually are vague and indistinct (Flohr Sørensen 2016). Even though deliberate fragmentation can comprise a meaningful process (Bolger 2014: 168; Burström 2013; Chapman 2000), it is only rarely that we try to find meaning and intention in the fragmentary and partial as an ontological fact.

This fractional aspect is especially apparent in visual culture. Because imagery normally represents or depicts something, it is bound to be reductive to some degree (Morreau 2002: 333). This does not mean that all images appear incomplete. Due to visual conventions and the perceptual closure effect, we are inclined to fill in details that really are not there (Minissale 2013: 6; Snodgrass and Kinjo 1998). None the less, certain images are partial in ways that stand out and affect people engaging with them. On the one hand, they can generate confusion, ambiguity and stress, but also promote curiosity and fascination and encourage subsequent actions on the other. The partial and the incomplete thus comprise potentially generative capabilities, that is to make things happen.

In this chapter, the potential generative aspects of partial Bronze Age rock art is examined. The examples are taken from the Bay of Mälaren 


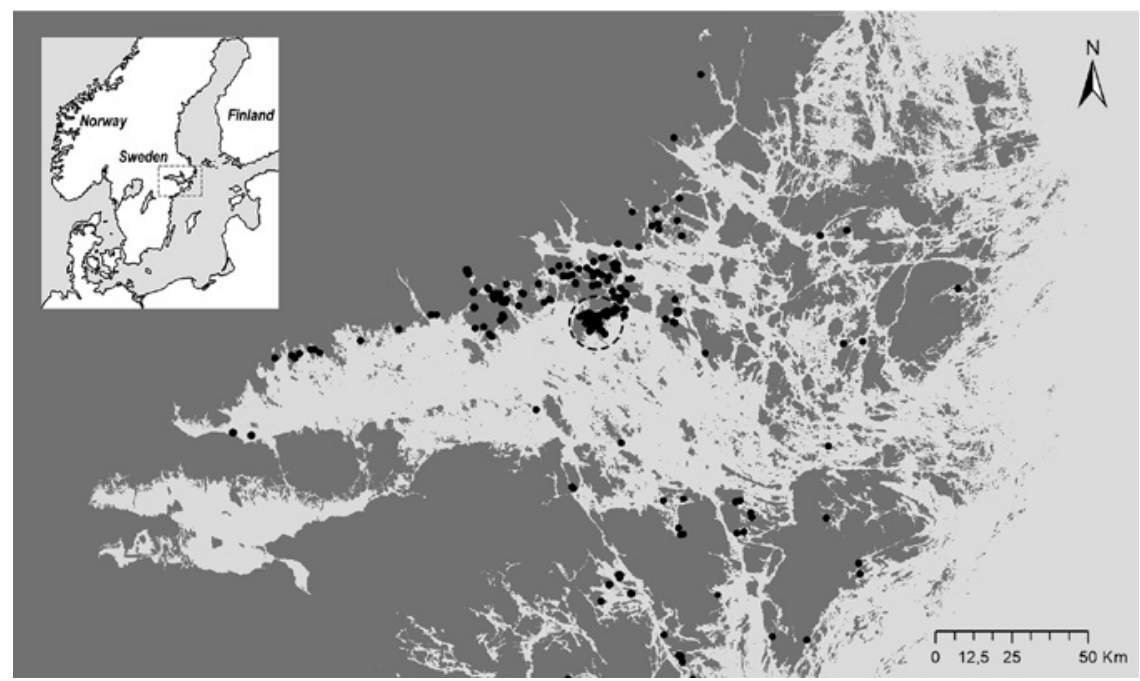

12.1 Map of the figurative rock art (black dots) in central eastern Sweden with the Boglösa area circled. The water level is adjusted to Early Bronze Age levels (24masl).

in central eastern Sweden in which an unusually high rate of partial petroglyphs is found (Fig. 12.1).

\section{Partial rhetoric in visual culture}

In art history and visual culture studies, partial or incomplete images primarily tend to be understood as unfinished. Images might be discarded first attempts, abandoned failures or pieces that were meant to be completed at a later stage (Baum 2016). There is, however, no simple dividing line separating what is finished and what is not. A work of art is not finished simply when the artist stops reworking and signs it (Jackson 2016: 33f). Consider, for instance, the varying level of detail in Titian's late works; was he experimenting with a non-finito style or are the paintings unfinished (despite the fact that they are signed)? Sketches, dummies and prototypes are sometimes regarded as independent works of art, too.

In modern art, reduction and abstraction are employed in various degrees as visual techniques. In the painting Mountain Saint-Victoire seen from Gardanne, Paul Cézanne deprived the fields of detail and schematically sketched the houses of the village, while Saint-Victoire is carefully outlined (Morvan 2006: 164). This play with focus emphasises the mountain and makes it stand out from the background. Other artists, 
such as Kandinsky and Paul Klee, work with a much higher degree of abstraction and reduction in order to expose 'what really is' (or should be) rather than how it appears (Ingold 2010: 21, 91). Munch also paints what for him is the essentials, which may give his paintings a sense of incompleteness (Jackson 2016: 33f). In abstract, impressionist and cubist art, objects are generally partial and distorted to induce effects. Francis Bacon, for instance, uses partial bodies in a triptych (1972) to create a sense of rhythm (Deleuze 2003: xv).

To portray objects and sceneries as fragmented or vague is an effective way to catch the viewers' attention as a 'punctum', as Roland Barthes describes it. A punctum is something that 'pricks' the beholder: something striking that 'rises from the scene, shoots out of it like an arrow, and pierces me' (Barthes 1981: 26f). In Cézanne's painting of the mountain Saint-Victoire, the varying levels of detail make the carefully portrayed mountain a punctum in relation to the less elaborated fields and houses. This technique of leaving a part out of the picture as a way to emphasise something is also employed in modern marketing. For example, business logos are sometimes consciously designed as partial to enhance the company's visibility. The partial logo is also argued to evoke a perceptual ambiguity, sending subliminal signals about the company as being innovative and progressive (Hagtvedt 2011; Hoyer et al. 2016).

The examples above illustrate how the partial and vague can be employed to affect people engaging with them. Such more or less conscious aspects of visual culture can be discussed in general terms as art function, aesthetics, agency or enchantment (Morgan 2018). It is, however, important to emphasise that this need not be intentional to be generative. Images produced for a specific purpose frequently take other paths when entering new relational networks or assemblages (see Mitchell 1996). In some ontologies, art also tends to be more than mere symbols and representations. Images can be considered animated, can work as portals, and in various ways can embody powers to change the world (Gell 1998: 6; Harman 2015; Fahlander 2018). Such potentially generative aspects of imagery vary depending on context and thus need to be discussed in specific terms. Because of their mediality (Belting 2005), petroglyphs comprise an especially interesting type of imagery in this case. The slow and laborious production process and limited iconographic range of motifs make petroglyphs well suited to a discussion about generative aspects of partial imagery.

\section{Partial boats and anthropomorphs in Boglösa}

Due to the schematic style of petroglyphs and the materiality of the rock, which does not encourage detailed elaboration, even fully fledged 
rock art figures are quite reductive as images. Because of the lack of colour, worked only with hammered-out fields, grooves and lines, petroglyphs constitute forms or shapes rather than images. The common boat motif, for instance, basically consists of four simple lines, which can be varied and embellished in assorted ways (especially the prows and the hull, see Fig. 12.6 below). Despite a quite extensive regional and temporal variation, the schematic simplicity makes the common motifs in south Scandinavian rock art easy to recognise. This quality may indeed have been one of the main reasons behind the choice of medium. However, looking more carefully at the panels, it is apparent that many of the motifs are incomplete in one way or another. They often lack one or two lines or a typical feature. A brief survey of the documented locales indicates that $c$. 15-20 per cent of the motifs in the research area miss out one or more essential elements. Normally, partial or fragmented rock art motifs are explained by weathering or wearing of the rock, which indeed is the case for many of the shallowly cut motifs. There are, however, a number of figures that apparently never have been 'complete'. Interestingly, this phenomenon is restricted to the boats and anthropomorphic motifs. There are a limited number of foot-soles and encircling motifs that sometimes lack parts of a line, but these are few in relation to the number of partial boats and anthropomorphs. Moreover, the zoomorphs found on the same panels are complete in the sense that they all have heads and four limbs - as well as ears and tails when appropriate. This predisposition towards boats and anthropomorphs is a clear indication that the partial motifs are not only due to the weathering of the rock.

The boat motifs are partial in various ways. Some lack details such as crew strokes, a hull line or a prow (Figs 12.2a and c). Others consist solely of crew-strokes or just two parallel lines (Figs. 12.2b and d). A common example is the 'half boats' that lack a bow or a stern (Fig. 12.2c). There are also a few examples of bow and stern, complete with keel and prow extensions that are not connected with hull lines (Fig. 12.2e). Whilst the majority of the boat motifs in the area can be considered 'intact', the anthropomorphs are only rarely portrayed with body, head, arms and legs. A few of them have extra attributes such as a shield, a sword or a phallus, but the majority of them (c. 70 per cent) none the less miss one or more limbs. The armless figures are particularly common, and are found in all major clusters of southern Scandinavian rock art (Almgren 1960: 52). Other motifs also miss the torso, and there are several examples of a pair of legs without a body (Fig. 12.3).

The fact that so many of the anthropomorphic and boat motifs are incomplete requires an explanation. Coles (2000: 30), who also noted the significant portion of partial boat motifs, suggested that they may 


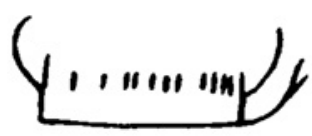

a

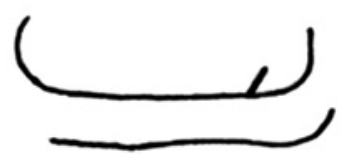

d
$\| 1111|1| 1$

b

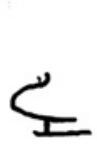

C

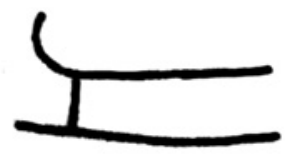

12.2 A variety of incomplete boat motifs that lack one or more lines or features. All examples taken from the Boglösa area.
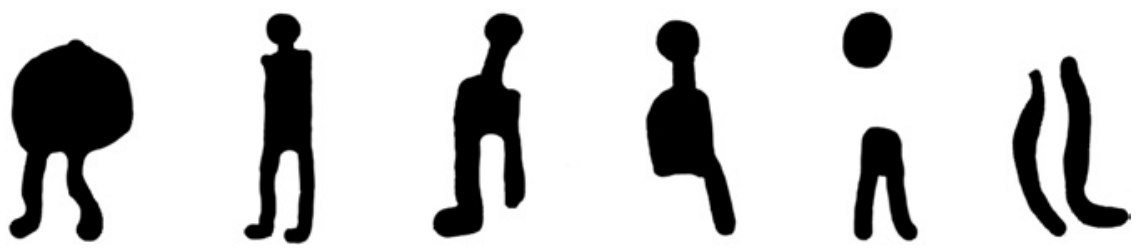

12.3 Examples of anthropomorphs with missing body parts (Boglösa 141, 94 and 73).

still have filled their purpose (see also Kjellén and Hyenstrand,1977: 16). Sometimes it may be enough to recognise two slightly bent lines as a 'boat'. There may even be a grammatical aspect behind the lack of certain elements of a well-known figure which conveys unknown meanings, that is, a half boat means one thing, and another without crew strokes something else, and so on. There is, however, no apparent pattern that suggests such a differentiated meaning in which various incomplete motifs can be read. Late Bronze Age rock art comprises some constellations that indeed could carry narrative aspects but, in the early part of the period, there is very little that supports such a scenario. In the Boglösa area, most panels consist of a few different motifs that have accumulated over the years, and the anthropomorphs are rarely involved in narrative constellations.

The production could also have been interrupted and abandoned for some reason, leaving the motifs unfinished. This could indeed be the case for some of the partial boat motifs. One such example concerns a two-metre-long boat motif with only eight crew strokes which in most other respects is similar to another of the same size with no fewer than 

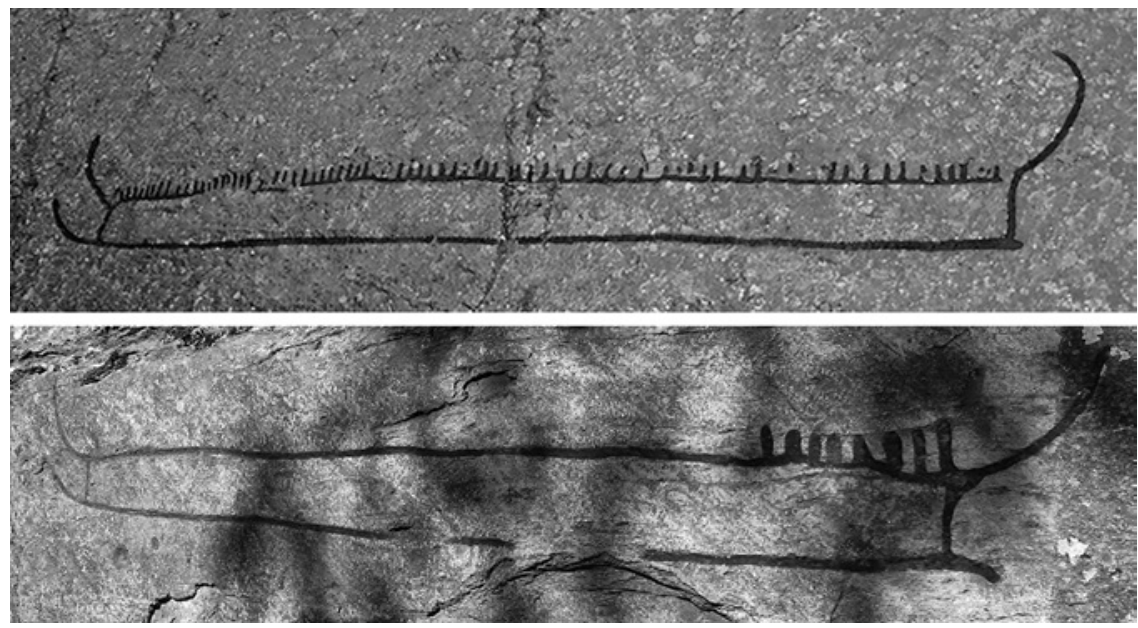

12.4 Finished and unfinished? Top: A two-metre long boat motif with 75 crew-strokes (Boglösa panel 109). Below: A similar-sized motif with only eight strokes (Boglösa 131:1).

75 strokes (Fig. 12.4). It is essential to appreciate the meticulous work behind the latter example, which equates to a serious amount of work. It reveals something about the meaning of rock art and the ontological status of the motifs. Making rock art is clearly not only about producing a specific type of motif but about doing it in different ways, in varying sizes, styles and levels of embellishment (Fahlander 2018: 72).

It is also possible that some partial motifs were momentarily left 'in process'. In visual magic, a figure is sometimes consecrated by a final addition that 'activates' the image and brings it into being (Freedberg 1989: 32). To leave a motif in an unfinished state can also make sense in terms of a propitiatory votive offering. The 'half' boats without bow or stern may represent the first stage of an offering, which is to be completed after the request has been fulfilled. The same could also be valid for the anthropomorphs. A figure without legs may be intended to be completed after the appeal for healing of a body part has been granted. It is, however, a less likely scenario when it comes to the anthropomorphs that consist only of a pair of legs or half a body. On the contrary, those cases rather suggest that some partial motifs are purposely made 'incomplete' from the start. There can be several reasons for doing so. In regard to Palaeolithic rock art, Hodgson has suggested that some animal motifs are made fragmented so as to mimic camouflaged animals. 'By drawing just-identifiable fragmented outlines, Palaeolithic artists were, in effect, using this kind of depiction to maximise implicit 
learning in order to achieve closure when the hunter encountered actual occluded fauna' (Hodgson 2003: 100). Besides the fact that Hodgson underestimates crucial aspects of hunting, such as movement and sound, such a hypothesis would none the less fit Bronze Age rock art poorly because the petroglyphs are already schematic from the start.

There have also been suggestions that some partial boat motifs could represent actual situations. For example, a half boat could refer to how a boat may appear when it enters an archipelago, and boats without hull-lines may illustrate sinking vessels (e.g. Goldhahn 2005: 590). The partial anthropomorphs could in a similar sense also be actual depictions of fragmented bodies. Lødøen (2015) has suggested that the incomplete skeleton-like anthropomorphs of the northern tradition of rock art relate to the incomplete bodies in Mesolithic burials. This might also be the case for the Bronze Age cremation burials, which involve a certain level of fragmentation of the dead (Röst 2016). The inhumations of the Early Bronze Age, however, are only rarely found disturbed. It has also been suggested that distorted representations of bodies may represent different states of consciousness of shamans (Hampson 2016: 117, see also Tilley 2008: 169).

None of the representational suggestions above can convincingly account for the high frequency of partial boat and anthropomorphic motifs in the research area. To be credible one would expect that the same interpretations should be valid for more than one of the types of motifs on the same panels, and to some extent also account for why only boats and anthropomorphs are partial. This lack of fit suggests that there may be other, subtler, reasons for producing partial motifs that do not hinge primarily on mimesis. As indicated in the introduction, the partial and incomplete can comprise a visual mode that depends more on what images do, rather than what they might depict. Partial motifs hang suspended in time as 'temporal itineraries' or materialities in becoming (see Deleuze and Guattari 1993; Joyce and Gillespie 2015). As the example of Francis Bacon illustrates, using partials can create rhythm, seemingly controlling movement, a coming to being, which emphasises the process of making art. We should thus be careful to make a too-sharp distinction between finished and unfinished petroglyphs. Instead of trying to find what lies behind the imagery, we are better off viewing them as 'as a process of growth' (Ingold 2013: 96; see also Gormley 2004: 131). Such becomings do not only involve repeated encounters between an artist and the rock, but also include generative aspects of all materialities engaged in the process (the rock, the tools, the milieu and the petroglyphs etc.). A most interesting aspect of the partial petroglyphs may thus lie in what they contribute to a relation; that is, how they may interact in social processes and sometimes even initiate a sequence of events. 


\section{Partial imagery as a visual mode}

Bronze Age rock art research has by tradition emphasised narrative, symbolic or representative aspects of imagery, which tends to reduce the petroglyphs to passive reflections or illustrations of ideology and cosmology. Despite the fact that the importance of context is emphasised, that is the landscape and the location of rock art in clusters along the shore, the imagery is surprisingly inert. In recent work on the materiality of rock art, some generative aspects of the imagery have been stressed in terms of agency (e.g. Fahlander 2012; Jones, 2006; Nimura 2016; Sapwell 2017). These discussions have unmistakable connections to symmetrical approaches that explore the distributed aspect of agency, and how materialities mediate in social processes (Fahlander 2008, 2017; Latour 2005; Jones 2012). Up to this point, however, much discussion on the materiality of rock art focuses on how specific motifs are employed as strategic symbols or on the fact that they may possess some kind of vague agency in 'magical' terms (e.g. Goldhahn 2010; Ling and Cornell 2010; Tilley 2004). In these texts, rock art is thus still 'read' as symbolic depictions that interact with each other or with the rock in presumed symbolic or narrative figurations. The partial figures are seen as fragments of something else and never as a visual expression on its own terms.

However, by stressing petroglyphs as material articulations, the dilemma of representation and resemblance can partly be bypassed to make room for analyses of what rock art actually does and how different visual modes affect the beholder (Fahlander 2013, 2018). It is, however, one thing to emphasise the mediality and materiality of art, but quite another to show such generative effects empirically. For instance, in Gell's (1998) scheme, rock art has secondary agency only within a specific cultural background (Layton 2003). Indeed, the potential generative effects of partial imagery can be argued to depend on a knowledge of what completed figures look like. This is, however, only partly true concerning partial petroglyphs, which due to their mediality can generate responses without any previous knowledge of Bronze Age visual culture. For instance, petroglyphs normally appear as vague lines and patterns in the rock. It does not matter if their origin is assumed to be natural, supernatural or human-made. The grooves in the rock can be evocative enough and when following the lines in the rock one can get fascinated or curious about where they might lead. When a line of a partial motif you follow unexpectedly stops, it would undoubtedly evoke a moment of surprise and curiosity, or incite a certain level of unease and insecurity.

We tend to view rock art as pictures, that is, something made to be perceived by other humans. However, petroglyphs may not be produced primarily to be experienced as images. As material articulations, 
petroglyphs are more likely to constitute magical contraptions with a specific aim to affect the world (see Gell 1998: 9). For example, the partial imagery can work as a maze-like device to confuse humans, animals and supernatural entities alike. In magical contexts, the function of maze-like imagery is generally for protection by confusing malignant powers. For example, to borrow a term from Gell (1999: 166), partial imagery can evoke a 'halo-effect'. Gell argued that elaborate art can create such an effect around certain objects. His main example concerns the complex carvings on the prows of the Kula canoes. The art was meant to dazzle the beholder and transform the canoes from mere vehicles to enchanted vessels of magical power. The more technically complicated and intricate the art is, the greater the halo-effect. In this case, however, the effect would emerge not from awe of skill but from the way a common motif is successfully enshrouded. In magical ontologies, hunting tools and traps are often embellished and decorated to lure or incite the human, animal or supernatural entity to 'give' itself to the hunter (Willerslev 2007: 102; Lemonnier 2012: 51). The allure of partial motifs can comprise a similar function to attract or capture something. The partial motifs may thus be involved in a particular type of vitalist technology with the aim to affect the animacy of the world in different ways (Fahlander 2018: 150ff; see also Jones 2012).

A partial image may also be considered a materialised exhortation for completion, that is, consciously made partial to encourage (or even demand) completion or other actions. Such secondary effects due to partial imagery are difficult to establish since not many of them are likely to leave tangible traces. There are none the less a few examples of secondary responses. One example concerns a partial zoomorphic motif that consists only of a pair of legs, a tail, a head and a neck, but without a body. By the aid of detailed laser scanning it has been possible to identify the addition of faint scratching marks over the area where the body should have been (Fahlander 2012: 103). Another case concerns a partial petroglyph at Himmelstalund, outside the modern city of Norrköping, where a half boat motif has been 'supplemented' by a row of Iron Age runes (Nilsson 2012: 87, Fig. 12.5).

However, to properly identify secondary actions in relation to incomplete figures we need to question in more depth what really is partial and what is complete. Holl (2002) has suggested that many seemingly finished motifs in African rock art actually represent different stages of the production. Simple contour-lined motifs, he argues, represent outlines that in later stages are completed with extremities and the decoration of the body with dots and lines. There are a number of instances in Bronze Age rock art where certain elements of the same motif seem to have been added at different occasions. For instance, elements of the boat motif (e.g. keel extensions and crew strokes) are sometimes cut in 


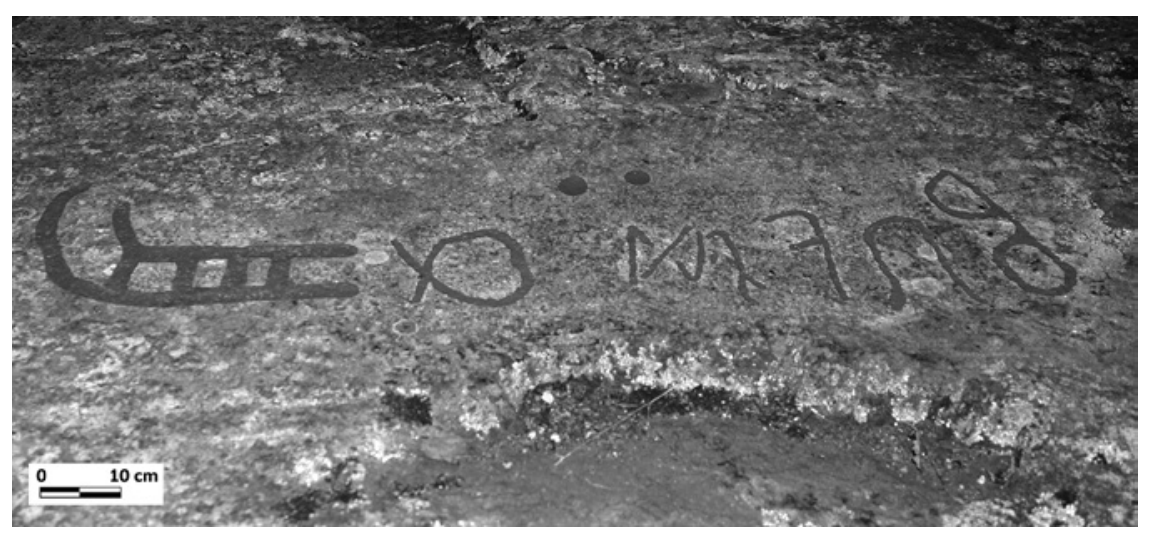

12.5 A partial boat motif at Himmelstalund, with an added row of Iron Age runes.

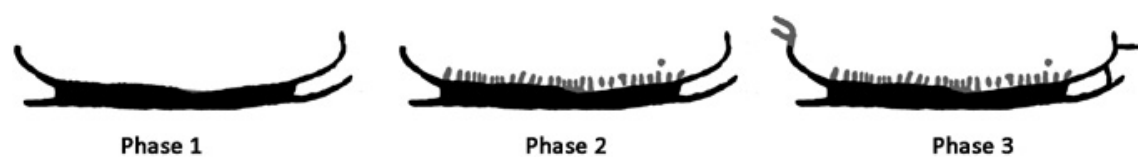

12.6 Example of a sequence in which details have subsequently been added to a seemingly complete motif (Boglösa 131).

lesser depth in relation to the main body (the hull, keels and prows). This is a tangible indication that key elements have been added to a motif at a later occasion (see also Milstreau 2017). The added (or original) elements of shallower-cut motifs can, in line with Holl's study, illustrate the becoming of a fully embellished and 'manned' boat in order to disarm, consecrate or finish it (Fig. 12.6). This might also be the case for the contour-cut motifs that are not yet hammered out (Fahlander 2012). There are thus indications that at least some petroglyphs are continuous projects that are never really 'finished'. In this case we can only speculate, for instance, whether making and using petroglyphs are individual or collective projects, or whether the main point lies in the continuation of certain motifs. Be that as it may, it is evident that the relation between partial or unfinished motifs is more complicated than first meets the eye. The partial petroglyphs can thus help to reveal essential indications of the meaning and purpose of rock art in general.

\section{Summary}

By studying petroglyphs as material articulations, and exploring issues of mediality and becoming, another dimension of Bronze Age rock art emerges. From such a perspective, the main aspect of petroglyphs is not 
primarily about mimesis and representation but about what they can do. The partial motifs comprise an interesting point of departure for such a 'processual' study. In the Boglösa area, the partial mode is restricted to boats and anthropomorphic figures, whilst zoomorphs and other motifs on the same panels are 'complete'. This shows that the partial motifs are not primarily the result of weathering of the rock or of interrupted production. On the contrary, it suggests that partial motifs indeed comprise a special type of visual mode in Bronze Age rock art.

The partial petroglyphs, however, are probably an entirely different matter from the modern artworks of Cézanne, Klee and Kandinsky. They are not likely to emphasise symbolic meanings or 'essentials', but the very effect, the punctum, of the fragmented and partial is none the less similar, despite different mediality and complexity. The closest analogy is perhaps the way in which modern marketing works with fragmented logos in order to generate the attention of the consumer and promote certain positive aspects of the company. Intentional or not, the 'partial effect' in Bronze Age rock art may indeed initiate both emotions and secondary actions. Partial motifs can catch the attention, incite anxiety and confusion, or evoke curiosity and promote completion or other secondary actions.

The incomplete motifs have either been deliberately made partial or have been left 'in progress'. For instance, some partial motifs may await consecration or the fulfilment of a votive request. Such a process is indicated on some panels where the different cutting depth of various elements is documented. Another interpretation of this phenomenon is that the incomplete motifs, intentionally or unintentionally, incite secondary action, in this case, the 'completion' of the motifs by adding features. Although it is difficult to show such effects of the partial motifs empirically, it is evident that they add important information about rock art in general, and stress the importance of viewing rock art as a process rather than a series of static images.

\section{Acknowledgement}

This study was made possible by generous funding from Riksbankens jubileumsfond (P16-0195:1).

\section{References}

Almgren, B. (1960). 'Hällristningar och bronsåldersdräkt', Tor 6, 19-50.

Barthes, R. (1981). Camera Lucida: Reflections on Photography. London: Vintage. Baum, K. (2016). Unfinished: Thoughts Left Visible. New York: Metropolitan Museum of Art. 
Belting, H. (2005). 'Image, medium, body: a new approach to iconology', Critical Inquiry 31 (2), 302-19.

Bolger, D. (2014). 'Gender, labor, and pottery production in prehistory', in D. Bolger (ed.), A Companion to Gender Prehistory. Hoboken, NJ: John Wiley \& Sons Inc. (pp. 161-79.).

Burström, M. (2013). 'Fragments as something more: archaeological experience and reflection', in A. González Ruibal (ed.), Reclaiming Archaeology: Beyond the Tropes of Modernity. London: Routledge (pp. 311-22).

Chapman, J. (2000). Fragmentation in Archaeology: People, Places, and Broken Objects in the Prehistory of South-eastern Europe. London: Routledge.

Coles, J. (2000). Patterns in a Rocky Land: Rock Carvings In South-west Uppland. Aun no: 0284-1347; 27. Uppsala: Uppsala University.

Deleuze, G. (2003). Francis Bacon: The Logic of Sensation. Minneapolis: University of Minnesota Press.

Deleuze, G. and F. Guattari. (1993). A Thousand Plateaus: Capitalism and Schizophrenia. Minneapolis: University of Minnesota Press.

Fahlander, F. (2008). 'Differences that matter: materialities, material culture and social practice', in H. Glørstad and L. Hedeager (eds), Six Essays on the Materiality of Society and Culture. Göteborg: Bricoleur Press (pp. 127-54).

Fahlander, F. (2012). 'Articulating stone: the material practice of petroglyphing', in I.-M. Back Danielsson, F. Fahlander and Y. Sjöstrand (eds), Encountering Imagery. Materialities, Perceptions, Relations. Stockholm: Stockholm University (pp. 97-115).

Fahlander, F. (2013). 'Articulating relations: a non-representational view of Scandinavian rock-art', in B. Alberti, A.M. Jones and J. Pollard (eds), Archaeology after Interpretation: Returning Materials to Archaeological Theory, Walnut Creek, CA: Left Coast Press (pp. 305-24).

Fahlander, F. (2017). 'Ontology matters in archaeology and anthropology: people, things and posthumanism', in J.D. Englehardt and I.A. Rieger (eds), These 'Thin Partitions': Bridging the Growing Divide between Cultural Anthropology and Archaeology. Boulder: University Press of Colorado (pp. 69-86).

Fahlander, F. (2018). Bildbruk i mellanrum: mälarvikens hällbilder under andra årtusendet fvt. Stockholm: Stockholm University.

Flohr Sørensen, T. (2016). 'In praise of vagueness: uncertainty, ambiguity and archaeological methodology', Journal of Archaeological Method and Theory 23 (2), 741-63.

Freedberg, D. (1989). The Power of Images: Studies in the History and Theory of Response. Chicago: University of Chicago Press.

Gell, A. (1998). Art and Agency: Towards an Anthropological Theory. Oxford: Clarendon Press.

Gell, A. (1999). The Art of Anthropology: Essays and Diagrams. London: Athlone Press.

Goldhahn, J. (2005). 'Slagsta revisited: en essä om behovet av subjektivt tolkande dokument', in J. Goldhahn (ed.), Mellan sten och järn. Göteborg: Göteborg University (pp. 581-600).

Goldhahn, J. (2010). 'Emplacement and the hau of rock art', in J. Goldhahn, I. Fuglestvedt and A.M. Jones (eds), Changing Pictures - Rock Art Traditions and Visions in Northern Europe. Oxford: Oxbow Books (pp. 106-26). 
Gormley, A. (2004). 'Art as process', in C. Renfrew, C. Gosden and E. DeMarrais (eds), Substance, Memory, Display: Archaeology and Art. Cambridge: McDonald Institute Monographs (pp. 133-51).

Hagtvedt, H. (2011). 'The impact of incomplete typeface logos on perceptions of the firm', Journal of Marketing 75 (July), 86-93.

Hampson, J. (2016). 'Embodiment, transformation and ideology in the rock art of Trans-Pecos Texas', Cambridge Archaeological Journal 26 (2), 217-41.

Harman, G. (2015). 'Art and OOObjecthood (a conversation with Christoph Cox and Jenny Jaskey)', in C. Cox, J. Jaskey and S. Malik (eds), Realism, Materialism, Art. Berlin: Sternberg Press (pp. 97-116).

Hodgson, D. (2003). 'Seeing the "unseen": fragmented cues and the implicit in Palaeolithic Art', Cambridge Archaeological Journal 13 (1), 97-106.

Holl, A. (2002). 'Time, space, and image making: rock art from the Dhar Tichitt (Mauritania)', African Archaeological Review 19 (2), 75-118.

Hoyer, W. D., D.J. MacInnis, and R. Pieters (2016). Consumer Behavior. Mason, $\mathrm{OH}$ : Cengage Learning.

Ingold, T. (2010). 'The textility of making', Cambridge Journal of Economics 34 (1) 91-102.

Ingold, T. (2013). Making: Anthropology, Archaeology, Art and Architecture. London and New York: Routledge.

Jackson, M. (2016). Work of Art - Rethinking the Elementary Forms of Religious Life. New York: Columbia University Press.

Jones, A. (2006). 'Animated images: images, agency and landscape in Kilmartin, Argyll', Journal of Material Culture 11 (1/2), 211-26.

Jones, A. (2012). 'Living rocks: animacy, performance and the rock art of the Kilmartin region, Argyll, Scotland', in A. Cochrane and A.M. Jones (eds), Visualising the Neolithic: Abstraction, Figuration, Performance, Representation. Oxford: Oxbow Books (pp. 79-88).

Joyce, R. and S.D. Gillespie. (2015). 'Making things out of objects that move', in R. Joyce and S.D. Gillespie (eds), Things in Motion: Object Itineraries in Anthropological Practice. Santa Fe, NM: School for Advanced Research Press (pp. 3-20).

Kjellén, E. and Å. Hyenstrand. (1977). Hällristningar och bronsålderssambälle $i$ sydvästra Uppland. Uppsala: Upplands fornminnesförening.

Latour, B. (2005). Reassembling the Social: An Introduction to Actor-Network-Theory. Oxford: Oxford University Press.

Layton, R. (2003). 'Art and agency: a reassessment', Journal of the Royal Anthropological Institute, 9 (3), 447-64.

Lemonnier, P. (2012). Mundane Objects: Materiality and Non-verbal Communication. Walnut Creek, CA: Left Coast Press.

Ling, J. and P. Cornell. (2010). 'Rock art as secondary agent? society and agency in Bronze Age Bohuslän', Norwegian Archaeological Review 43 (1), 26-43.

Lødøen, T. (2015). 'Treatment of corpses, consumption of the soul and production of rock art: approaching Late Mesolithic mortuary practices reflected in the rock art of Western Norway', Fennoscandia Archaeologica 32, 79-99.

Milstreu, G. (2017). 'Re-cut rock art images (with a special emphasis on ship carvings)', in S. Bergerbrant and A. Wessman (eds), New Perspectives on the Bronze Age. Oxford: Archaeopress (pp. 281-8). 
Minissale, G. (2013). The Psychology of Contemporary Art. Cambridge: Cambridge University Press.

Mitchell, W.J.T. (1996). 'What do pictures really want?', October 77 (summer 1996), 71-82.

Morgan, D. (2018). Images at Work: The Material Culture of Enchantment. New York: Oxford University Press.

Morreau, M. (2002). 'What vague objects are like', The Journal of Philosophy 99 (7), 333-61.

Morvan, B. (2006). Impressionism. Paris: Terrail.

Nilsson, P. (2012). 'The beauty is in the act of the beholder', in I.-M. Back Danielsson, F. Fahlander and Y. Sjöstrand (eds), Encountering Imagery: Materialities, Perceptions, Relations. Stockholm: Stockholm University (pp. 77-96).

Nimura, C. (2016). Prehistoric Rock Art in Scandinavia: Agency and Environmental Change. Oxford: Oxbow Books.

Röst, A. (2016). Fragmenterade platser, ting och människor: stenkonstruktioner och depositioner på två gravfältslokaler i Södermanland ca 1000-300 f Kr. ['Fragmented places, things and people: Stone constructions and deposits in two burial grounds in Södermanland, c. 1000-300 BCE']. Stockholm: Stockholm University.

Sapwell, M. (2017). 'Understanding palimpsest rock art with the art as agency approach: Gell, Morphy, and Laxön, Nämforsen', Journal of Archaeological Method and Theory 24 (2), 352-76.

Snodgrass, J.G. and H. Kinjo. (1998). 'On the generality of the perceptual closure effect', Journal of Experimental Psychology: Learning, Memory, and Cognition 24 (3), 645-58.

Tilley, C. (2004). The Materiality of Stone: Explorations in Landscape Phenomenology. Oxford: Berg.

Tilley, C. (2008). Body and Image. Explorations in Landscape Phenomenology II. Oxford: Berg.

Willerslev, R. (2007). Soul Hunters: Hunting, Animism, and Personhood among the Siberian Yukaghirs. Berkeley: University of California Press. 